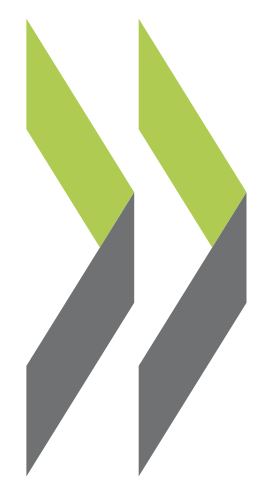

OECD Science, Technology and Industry Working Papers 2019/07

\title{
Industrial robotics and product(ion) quality
}

\section{Timothy DeStefano,} Koen De Backer, Jung Ran Suh 


\section{OECD Science, Technology and Industry Working Papers}

The release of this working paper has been authorised by Andrew Wyckoff, OECD Director for Science, Technology and Innovation and by Laurence Boone, OECD Chief Economist.

OECD Working Papers should not be reported as representing the official views of the OECD or of its member countries. The opinions expressed and arguments employed are those of the authors. Working Papers describe preliminary results or research in progress by the author(s) and are published to stimulate discussion on a broad range of issues on which the OECD works. Comments on Working Papers are welcomed, and may be sent to Directorate for Science, Technology and Innovation, OECD, 2 rue André-Pascal, 75775 Paris Cedex 16, France.

This document, as well as any data and any map included herein, are without prejudice to the status of or sovereignty over any territory, to the delimitation of international frontiers and boundaries and to the name of any territory, city or area.

(C) OECD 2019

You can copy, download or print OECD content for your own use, and you can include excerpts from OECD publications, databases and multimedia products in your own documents, presentations, blogs, websites and teaching materials, provided that suitable acknowledgment of OECD as source and copyright owner is given. All requests for commercial use and translation rights should be submitted to rights@oecd.org. 


\title{
Industrial Robotics and Product(ion) Quality
}

Timothy DESTEFANO, Koen DE BACKER and Jung Ran SUH

\begin{abstract}
The following report examines the importance of industrial robotics as a driver of production and trade quality. In an attempt to peer below the aggregate surface of traditional industrial GVC indicators, the paper relies on 6 digit product level trade data to assess the extent to which industrial robotics influence the quality of exported and imported goods for developed and emerging economies over the last two decades. The results demonstrate that robotics contribute to increasing quality of exports however the effect is somewhat nuanced between high income and emerging economies. For high-income countries the diffusion of robots is linked with an increase in within product quality, however for emerging economies quality gains appear to be somewhat more pronounced between products. At the same time, robotics appear to have little or no effect on import quality or on the concentration of exports and products for either type of economy.
\end{abstract}




\section{Table of Contents}

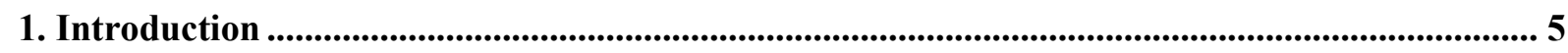

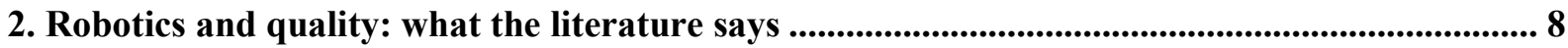

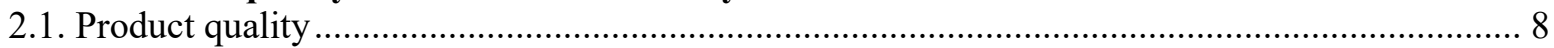

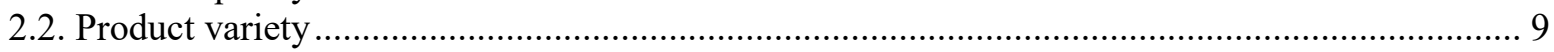

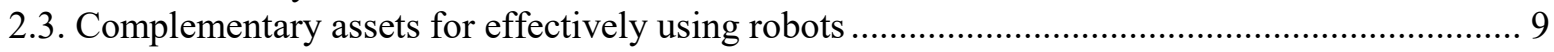

3. Robotics and trade quality: what the data shows................................................................................ 13

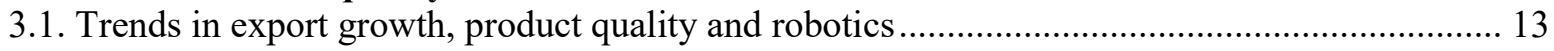

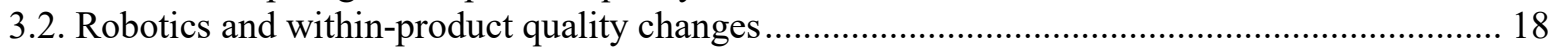

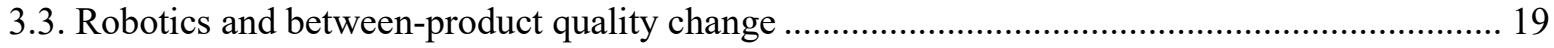

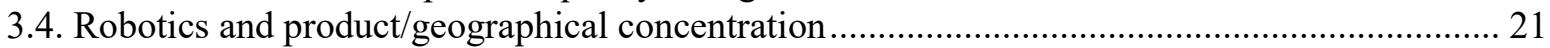

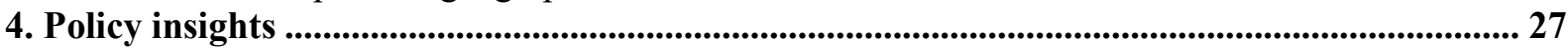

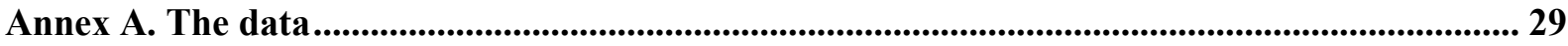

Annex B. Economy and industry coverage ............................................................................................ 32

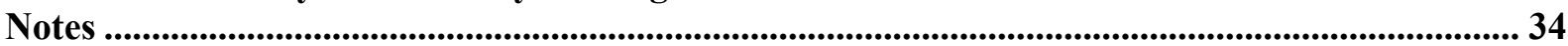

Tables

Table 1. Growth in robot stock on the within-product growth of export quality (exports of all goods)19 Table 2. Growth in robot stock on the within-product growth of import quality (imports of intermediates)

Table 3. Growth of robot stock on between-product changes of export quality (exports of all goods) 21

Table 4. Growth of robot stock on between-product changes of import quality (imports of intermediates)

Table 5. Growth of robot stock on change in geographic concentration of exports and imports (intermediates).

Table 6. Growth of robot stock on change in product concentration of exports and imports (intermediates)

Figures

Figure 1. Robot stock in top 10 using economies. 5

Figure 2. Growth in quality and exports by industry, 1993-2015 .................................................... 14

Figure 3. Growth in product quality and exports, at the product level, 1993-2015 ........................... 15

Figure 4. Robot stock and export quality by industry, 1993-2015 ................................................. 17

Figure 5. Within- and between-product changes in quality growth by industry, 1993-2015 .............. 20

Figure 6. Changes in geographic and production concentration of exports, by industry, 1993-2016 .. 23

Figure 7. Changes in geographic and product concentration of intermediate imports, by industry, 19932016 .

\section{Boxes}

Box 2.1. Case study examples of robot use and quality gains. 


\section{Introduction}

Industrial robotics are becoming an integral component in the production processes of many firms around the world. In 2016, the sale of industrial robots ${ }^{1}$ reached over 290000 units and is expected to increase to 1.4 million units in the next three years (Figure 1, IFR, 2017; IFR, 2016). In combination with important advances in a number of complementary technologies, greater adoption of robotics is believed to be a key element in fostering "a next production revolution" OECD (2017). The growing investment in robotics is one aspect of the increasing digitalisation of the economy and society, fundamentally changing the outlook of manufacturing industries across the globe. Governments in OECD and emerging economies are betting heavily on robotics to safeguard the competitiveness of their manufacturing industries, frequently supported by (direct) government support for research and adoption of robotics.

Figure 1. Robot stock in top 10 using economies

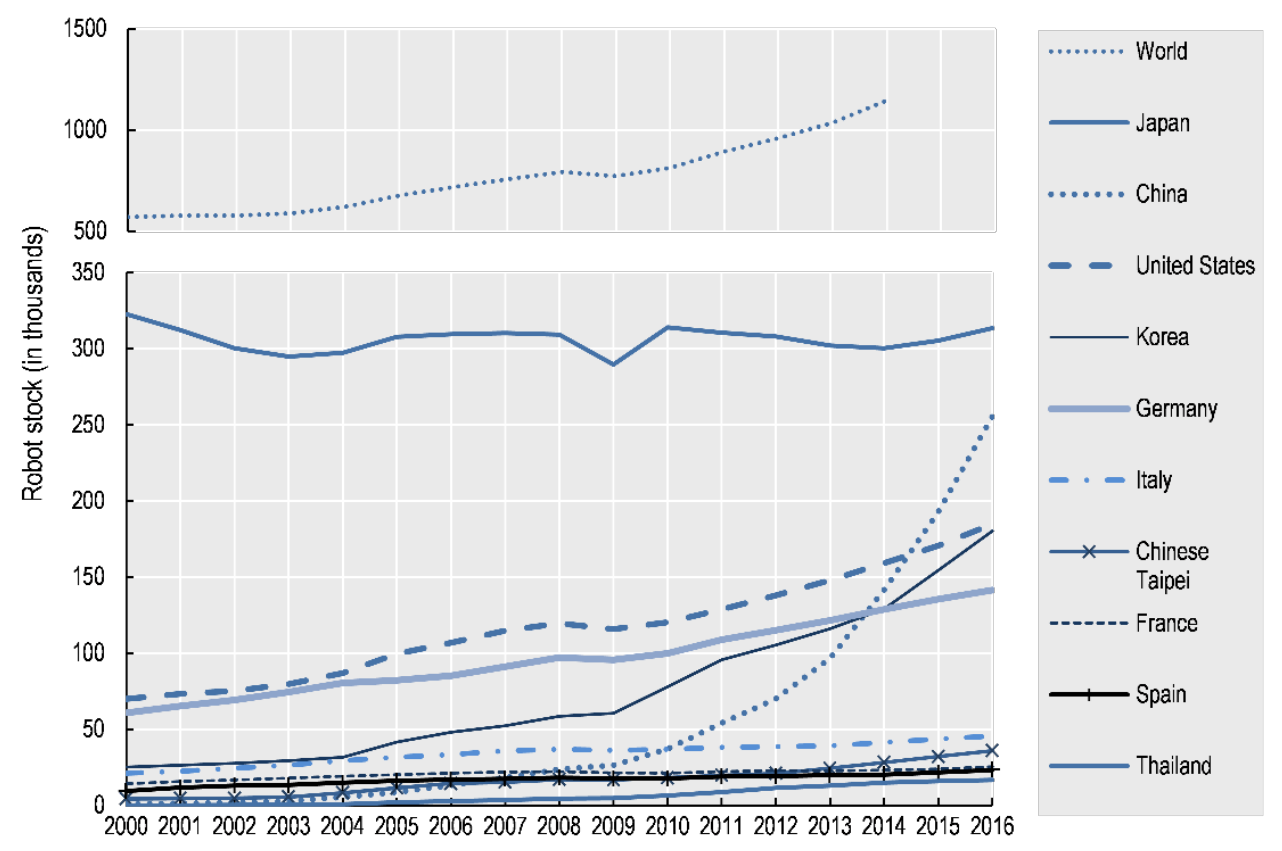

Note: Robot stock is calculated using a perpetual inventory method assuming an annual depreciation of $10 \%$. World robot stock from 2013 is absent from the IFR dataset.

Source: Calculations based on IFR (2016).

A previous paper (De Backer et al., 2018) has shown that investment in robotics slow down the rate of offshoring, hence may - ceteris paribus - also stall the further expansion of GVCs. The falling price of robotics together with their fast-rising dexterity makes offshoring and the international sourcing of intermediates less attractive relative to domestic production involving robotics. The potentially negative effect of robotics on offshoring has however only occurred within the last few years - reflecting the recent surge in robotics investment, and thus far is only directly observable in OECD economies and in 
more labour-intensive industries. At the same time, the paper finds no evidence that robotics are already resulting in reshoring activities back to OECD economies that have previously been offshored.

This follow-up paper, attempts to analyse in more detail the effect of robotics on the quality dynamics of global manufacturing across countries. In addition to affecting the quantity of international sourcing and intermediates trade, robotics may also affect the quality and characteristics of the production process, its output and intermediates (sourced from abroad). Anecdotal evidence at the firm-level (see below) shows that robotics significantly change the production technology, hence also the inputs and outputs of production processes. This paper therefore analyses the effect of robotics on the quality of intermediate imports and exports in manufacturing industries over time.

Overall, industrial robotics allow firms to produce products with greater precision, at higher levels of consistency, and with fewer product defects, facilitated by built-in quality assurance checks. In addition, given the greater precision and longer run times offered by automated machines (in some cases continuous production), the use of robots in the production process may require higher quality inputs, helping firms to produce higher quality products (IFR, 2017). Furthermore, the use of robots may enable firms to produce new and greater varieties of products due to the increased flexibility and mobility of these reprogrammable machines (PWC, 2014; Michalos et al., 2016; and Michalos et al., 2015).

While the policy relevance of the previous papers drafted for this project (De Backer et al., 2018) focused on the impact of robotics on the location of production and the development of GVCs, the policy angle of this paper is more related to the upgrading discussion within GVCs. Previous analysis, in and outside OECD, has shown that in order to fully benefit from GVCs, industries and economies need not only to participate in GVCs but also upgrade their activities within GVCs. Upgrading across different dimensions - process, product, functional and chain upgrading - allows countries to create and capture more value from their activities in GVCs. While GVC upgrading can be described in terms of different indicators, it is clear that increases in the quality of exports (and intermediate imports) are a reflection of any of the four upgrading trajectories.

The ability of countries to produce and export higher quality goods has attracted a lot of attention because of its importance for the development and growth of an economy (Hirschman 1958; Rosenstein-Rodan; 1943; Grossman and Helpman 1991; Matsuyama 1994; Hidalgo et al 2007). At the firm-level, the literature suggests that businesses which produce higher quality goods, obtain higher revenue and sell their goods to a greater variety of markets (Manova and Zhang 2012; Crozet et al 2011). Increasing the quality of production and trade is also linked with employment and salaries. Verhoogen (2008) for example finds that firms who produce high quality goods are more productive and also pay higher wages in order to retain their high skilled workforce. Moreover, production quality is found to be a strong predictor of the competitiveness of exporters (Verhoogen 2008). The quality of production and the value added to exported goods is therefore a top priority to policy makers.

The economic literature has not only discussed the effects of product(ion) quality but also analysed its determinants. The supply of skilled labour and capital as well as the development level of an economy have been identified as important factors (Schott 2004; Hummels and Klenow 2005; Hallak 2010). In addition, it has been reported - not surprisingly - that high quality production requires higher quality inputs, which often need to be sourced from abroad (Kugler and Verhoogen 2012; Hallak and Sivadasan 2013). Directly linked to that, the development of supplier networks and trade liberalisation have 
been discussed to be important drivers of trade quality (Henn et al 2015; Bas and StraussKhan 2015). Also institutional quality is found to be positively correlated with export quality (Henn et al 2015).

Within this broader discussion on the determinants of export quality and intermediate inputs, this paper focuses on the impact of a particular type of capital as a potential determinant. The growing investment and adoption of robotics, which themselves are increasingly characterised by higher quality and greater dexterity, is expected to alter the production process and as such also the trade performance of industries and economies within GVCs. In particular, greater use of robotics is likely to result in higher quality exports and imports, including the variety and composition of the export/import portfolio.

The main findings are of the paper are:

- The effect of robotics on product quality takes place along different dimensions in developed and emerging economies.

- For developed economies, robot adoption is positively related to within-product quality changes, i.e. quality enhancement of individual products for developed economies.

- Quality increases are also observed on the import side of intermediates, indicating that the adoption of robotics requires also higher quality inputs in developed economies.

- In emerging economies, robot adoption is associated with quality changes both for within-product as well as between product changes. Thus, in addition to quality enhancement of existing products, robotics is also associated with a restructuring of countries' trade portfolios towards higher quality products. 


\section{Robotics and quality: what the literature says}

While the economic literature is beginning to consider the role of robotics in modern economies, empirical analysis remains limited. An exception is the rapidly growing number of studies discussing the employment impacts of robotics. Nonetheless, a number of important insights arise from the robotics engineering literature that has discussed the link with production quality already for a long time. Evidence shows that robots have become a key input in the production of certain high quality products in the automotive, aeronautical and electronics sectors. Analysing more aggregate data, Graetz and Michaels (2015) showed that robot adoption has resulted in greater output, value added and total factor productivity, which is in turn an important determinant of whether firms export (Bernard and Jensen, 2000; Bernard et al., 2014). Robot adoption may therefore be important for OECD countries looking to stay competitive and emerging countries hoping to achieve greater economic performance through the production and trade of higher quality products.

\subsection{Product quality}

The ability of industrial robotics to standardise quality and produce and assemble new complex products are important quality benefits of robotics. Furthermore, robots can considerably reduce the time of production while at the same time increasing the efficiency of the production process. Painting robots used by Boeing reduce the time it took a team to paint the wing of a Boeing 777 from 4.5 hours to 24 minutes (Gates 2013). In addition, robots have been observed to enable firms to produce more complex goods with greater precision, resulting in higher quality products (IFR 2016; (EU 2014; Argote and Goodman 1985; Guest 1984; Ayres and Miller 1983). Industrial robotics are continuing to improve, carrying out repetitive tasks at higher rates of accuracy, with further improvements in the coming years are expected (EU 2014; Valente et al 2017). Robotics also allow for greater accuracy and precision when tasks are not repetitive and when the industrial environment is less than ideal, e.g. through the use of vision guided machines (Agapakis et al 1990 and Gunasekaran 1996).

Another dimension of product quality relates to complexity, which may also be enhanced by robotics. In the IT industry for example, robots and automated machines enable greater complexity in products, particularly since these tools help reduce the size of internal components used to produce goods (Popovic 2009). Moreover, CAD/CAM technologies are used alongside robotics during the design and testing phases of production, allowing producers to virtually create more sophisticated prototypes that can be tested through simulations, increasing the quality and variety of final goods (Buxey, 1991; Milgrom and Roberts, 1990; Groover and Zimmers, 1983; Evans, 1980).

Another mechanism through which robotics may influence the quality of production is by reducing production error (McKinsey, 2017). A number of robots are able to carry out quality control inspections that can help reduce the numbers of flawed products, while at the same time reducing the need for quality inspection staff (Argote and Goodman, 1985). Sensory and vison devices incorporated within robotics allow the machines to identify flaws in products across a number of dimensions including colour, surface finish, and 
abrasions (Herakovic et al., 2011; Herakovic, 2010). The automotive industry, for example, relies on robots to monitor quality through a host of production processes such as defaults in body panels, uneven paint finishes, breaks in adhesive sealants, irregular welding beads, all of which are found to increase the quality of the end product (Bogue 2013). Within the food industry, automated machines with optical sensors and spectroscopic techniques are incorporated in processing and inspection of food products by providing instantaneous safety and quality control assessment (Singh and Jayas, 2012).

Production by industrial robotics require overall higher quality inputs. Long run times coupled with consistent precision means that the inputs used within the production process need to be of higher quality. Welding robots, for example, run for long periods of time at high temperatures requiring producers to use high quality consumable inputs in order to prevent process breakdowns, unneeded maintenance and to ensure that the production process is efficient and accurate (The Fabricator, 2011).

\subsection{Product variety}

Incorporating robots within the production process can also influence the variety of goods that firms produce. For example, robots enable firms to apply more adjustments - more efficiently - on the manufacturing floor, switching from producing a vintage product to a new good, and thus enhancing the product mix (Argote and Goodman, 1985). This helps companies to react to fast-changing (consumer) demand and realise shorter product lifecycles (PWC, 2014).

Greater reliance on mobile robots in the future is expected to result in even greater production flexibility. Unlike traditional stationary robots, mobile robots can be easily relocated throughout the production facility and reconfigured to carry out new tasks and use new tools quickly to markedly enhance product variety (Michalos et al., 2016; Michalos et al., 2015).

\subsection{Complementary assets for effectively using robots}

While there are a number of ways that robotics can influence production and trade quality, simply adopting the technology does not typically result in the expected gains. Human capital - in particular IT specialists - is a crucial element for effective robot use. Every function of a robot, or a cluster of robots working collectively, still needs to be coded by a high-skilled employee (IFR 2017). The recent introduction of more economical selfprograming robots will reduce to some extent the need for IT specialists and programmers, although this is a very recent trend. ${ }^{2}$

A qualitative business review (see Box 2.1) provides illustrative examples of how robotics and other digital technologies, such as smart sensor, cloud computing, AI, are being integrated into robot working systems. Connectivity, optimisation, agility and proactivity are crucial features characterising smart factories (Deloitte, 2017). Manufacturing executive system (MES) and cyber physical system (CPS) are representative systems used in robot operation. MES is the computerised system used to track and document the flow of raw materials to final goods. Information on resource scheduling, order execution, production analysis is managed by this system. CPS is a system that combines and coordinates physical and virtual elements. In the CPS system, hardware and software components are deeply integrated with each other (Mikusz and Csiszar 2015). Sensors are used to track real time movements and work-in-progress. Cloud computing along with advances in the Internet of Things (IOT) can be employed alongside robots to collect and 
process data, then communicate this to other machines on the production line. A combination of these systems enables real time monitoring of the production process that can predict potential quality defects before they occur.

Adoption of these systems help advance the function of traditional robots from tedious and repetitive tasks to more sophisticated, precise and autonomous work. Under these systems, highly skilled personnel are required to decide what data to use and how to handle the volume and velocity of data. Skilled labour are also required to maintain, repair, manage and develop robotic technologies (PWC, 2014). 


\section{Box 2.1. Case study examples of robot use and quality gains}

A review of the literature on robotics and product quality helps to illustrate broad economic gains achieved through the use of this technology. But in order to provide specific examples of the ways firms are integrating these machines into their production facilities and how higher product quality is achieved, a number of case studies from Korean firms are presented below.

Dong Yang Piston, established in 1967, is a manufacturer of core automotive parts and pistons for engines. The company employs around 1,040 people and its total sales amounted to USD 314 million in 2016. About $80 \%$ of their sales come from exports with products sold to North America, Japan, Europe and Asia. Its domestic market share is above 50\% and its global market share ranks 4th. Their largest customers are Hyundai, BMW, Audi, GM, Ford, GM and Chrysler. Dong Yang Piston has established subsidiary companies in People's Republic of China, Mexico and the United States. Dong Yang Piston began to adopt robotics in 1995 in order to guarantee consistent quality and enhance productivity. Robotics were implemented at various stages of production including casting, machining, drilling, surface treatment and assembling in production, particularly for repetitive manual and potentially hazardous tasks. In the casting phase, robots are used to dip molten metal into molds while also monitoring in real time the quality of the production process. In the machining and assembling process, the company uses a gantry robot, which executes tasks that previously required ten employees. These machines are also found to enable greater product variety. The robotics, connected with sensor and monitoring systems led to an increase in the variety of piston products: from 72 items in 2010 to 115 items in 2016. Establishing a system that tracks and traces each component along a production line allows for controlling of quality beforehand and has led to a zero error rate. Furthermore, robotics have reduced the change time between products, minimised the down time of facilities and enhanced product precision. The company has also reduced the scrap rate by 90\% between 2010 and 2016. Overall Dong Yang Piston believes that the use of robots helped increase quality control resulting in greater customer satisfaction and larger orders from global customers.

Yonwoo is a cosmetics packaging company, which is often cited as having implemented best practices for increasing quality control and product flexibility through robotics (KIRIA 2016). Founded in 1983, Yonwoo manufactures packaging materials for cosmetics and other daily suppliers. The company has 1,514 employees with sales of 194.1 USD million in 2016 and a product line including more than 9,000 products. They sell plastic cosmetic containers to more than 400 cosmetic companies globally including L'Oréal, Estée Lauder, and Amore Pacific, LGH\&H. As of 2016, exports accounted for $41 \%$ of sales. Yonwoo recently automated its anodising process with robots for the production of dispenser pumps and cosmetics containers in order to improve quality and ensure the safety of workers. Anodising is an electrochemical process that converts the metal surface into a decorative, durable, corrosion-resistant, anodic oxide finish. It is accomplished by immersing the aluminium into an acid electronic bath and passing an electric current. By using anodising robots Yonwoo has reduced their error rate from 2.7 to $0.12 \%$ between 2016 and 2017 while maintaining consistent product quality. At the same time, the rate of industry accidents has fallen from 2.8 to $0 \%$ and product per hour output has risen from 4,000 to 6,300 units. The use of these machines also resulted in the reduction of the workforce by roughly $50 \%$.

The Cheong-Ju plant of LS industrial System's (LSIS) is one of the most advanced automated production facilities in Korea. Most of the production lines are automated including parts supplying to assemble lines, testing and packaging and so on. The LSIS Cheong-Ju plant specialises in the 
production of low-voltage circuit breakers and magnetic switches. It began implementing robots and ICT systems in 2011. Through the use of robotics and digital technologies, the LSIS Cheong-Ju plant is producing higher output, while at the same achieving product diversification, customisation and small quantity batch production. Since 2017, low-voltage circuit breakers and magnetic switchers are automatically manufactured producing roughly 26 million units per year. During this process, program controllers connected to ICT and manufacturing execution systems, collect data and monitor production in real time. Automated vehicles transport products and robotics with detection sensors package goods. Robots are used to analyse quality control tests thereby improving the precision, consistency and quality of products. The Cheong-Ju plant also uses advanced planning systems that enable the planning of orders, production and materials to ensure flexible fabrication. In general, the use of robotics along with digital technologies enhanced the quality of the entire manufacturing process. For example, cycle times were cut in half, approximately from 10 seconds to 5 seconds and productivity increased 3 fold. The number of product defects decreased from 368 parts per million (ppm) to $8 \mathrm{ppm}$ while energy usage was cut by 60 per cent. The amount of labour used for production has also decreased: in the early 2000s 8 people worked on the production line while today only one person is required to supervise the quality of final products. LSIS was expecting to have $100 \%$ automated production lines by September 2018.

Posco is a large steel producer that introduced a smart factory system including robotics, AI and a virtual factory for their production process. Steel-consuming industries such as automobiles, ecoships, and smart ships increasingly request higher quality steel products in terms of strength, corrosion resistance and performance. To meet these requirements, the Posco plant at Gwang Yang Steel installed in 2015 a data integration infrastructure that is able to pre-emptively detect or predict faults and abnormalities. Smart sensing, smart analysis and smart controls provide real time data collection and analysis, while controlling and detecting defects. The automatic regulation of blast furnace temperatures, the optimisation of the air-fuel ratio in hot rolling mills, the precision control of deformation during quenching and the prediction of optimal coating weight have enabled the company to produce high quality and consistent products. Coating weight control technology was implemented in the Gwang Yang plant to achieve consistent thickness of coating layer. Maintaining each steel sheet's flatness is an essential factor for the quality of steel products. Manual controls that are heavily dependent on the skills of workers can lead to deviations of thickness and surface defects. Coating weight control automation systems help to reduce the inconsistency of the coating weight thereby enhancing the accuracy and stability of the final product. In particular, the differences in coating weight per square meter were reduced from 7 grams (under manual operation) to 0.5 grams (under automated operations). 


\section{Robotics and trade quality: what the data shows}

\subsection{Trends in export growth, product quality and robotics}

The empirical analysis in this paper brings together data from different sources in order to assess the effect of robotics on the quality of exports (and imports). In a similar manner as De Backer et al. (2018), data on robotics, which are available at the country-industry level, come from the International Federation of Robotics. The dataset contains information on robot adoption in manufacturing industries across OECD and emerging economies up to 2016.

The measures of export/import quality - central in the analysis - are calculated using 6digit product-partner level trade data, developed in the OECD database on Bilateral trade but based on UN data. While traditional GVC metrics such as the domestic value added content in exports (used in De Backer et al. (2018) are useful in providing a broad understanding of changes in value added to exports and imports, it is not always entirely clear how such "quality" gains are achieved. Changes in export and (intermediates) import quality - based on the Khandelwal (2010) measure of quality-are calculated at the productpartner level as well as the aggregate industry level (weighted across products and partners by trade volumes).

Figure 2 presents the increase in product quality at the industry level for the groups of developed and emerging economies. The data demonstrate that product quality of exports has risen across most industries in both group of countries; emerging economies show overall stronger increases in product quality. Maybe surprisingly particularly in light of the literature discussed above, the data do not seem to suggest a strong association between changes in product quality and export growth: industries that report the strongest increase in product quality do not necessarily report the largest growth in exports.

However, a closer link between product quality and export growth is observable at the product level (Figure 3). For both of the groups of developed and emerging economies, a (strong) positive correlation is observed. The data at the product level also show that a considerable number of products have actually decreased in quality over the considered time period. All this suggest the need for analysing changes in product quality at the industry as well as at the product level in order to fully understand the dynamics taking place over time. 
Figure 2. Growth in quality and exports by industry, 1993-2015

Developed economies
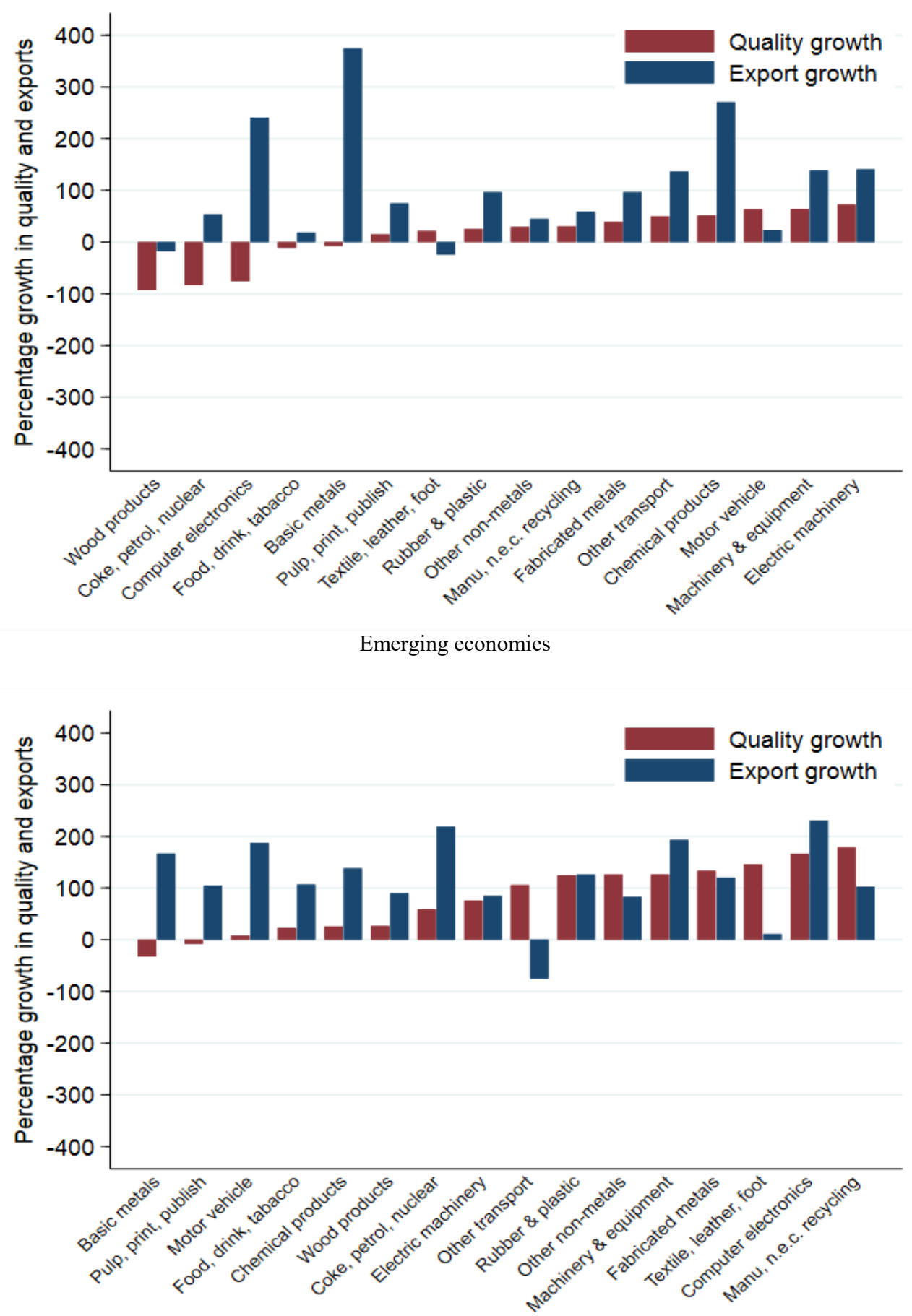

Note: This figure illustrates the growth in quality and exports (weighted across countries) for developed and emerging economies over the periods 1993-2015 and 2000-2014, respectively. 
Figure 3. Growth in product quality and exports, at the product level, 1993-2015

Developed economies

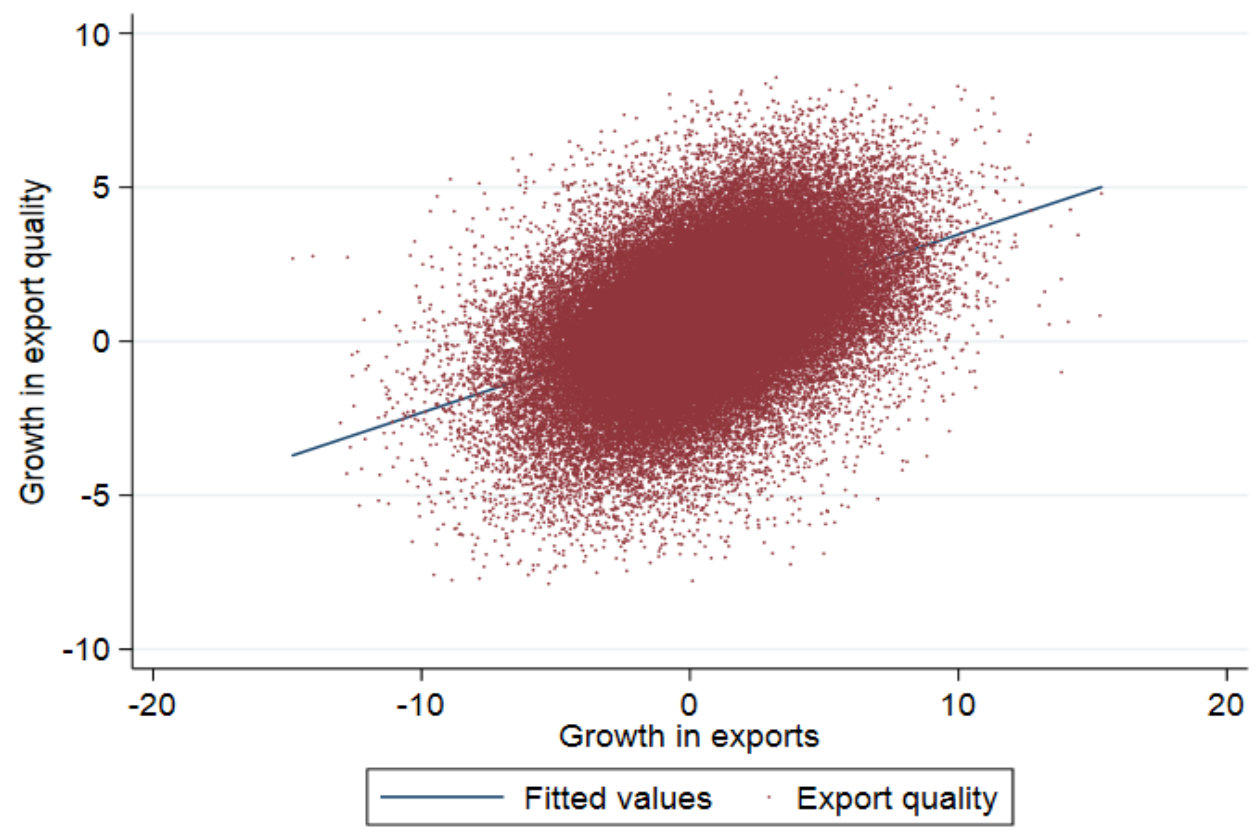

Emerging economies

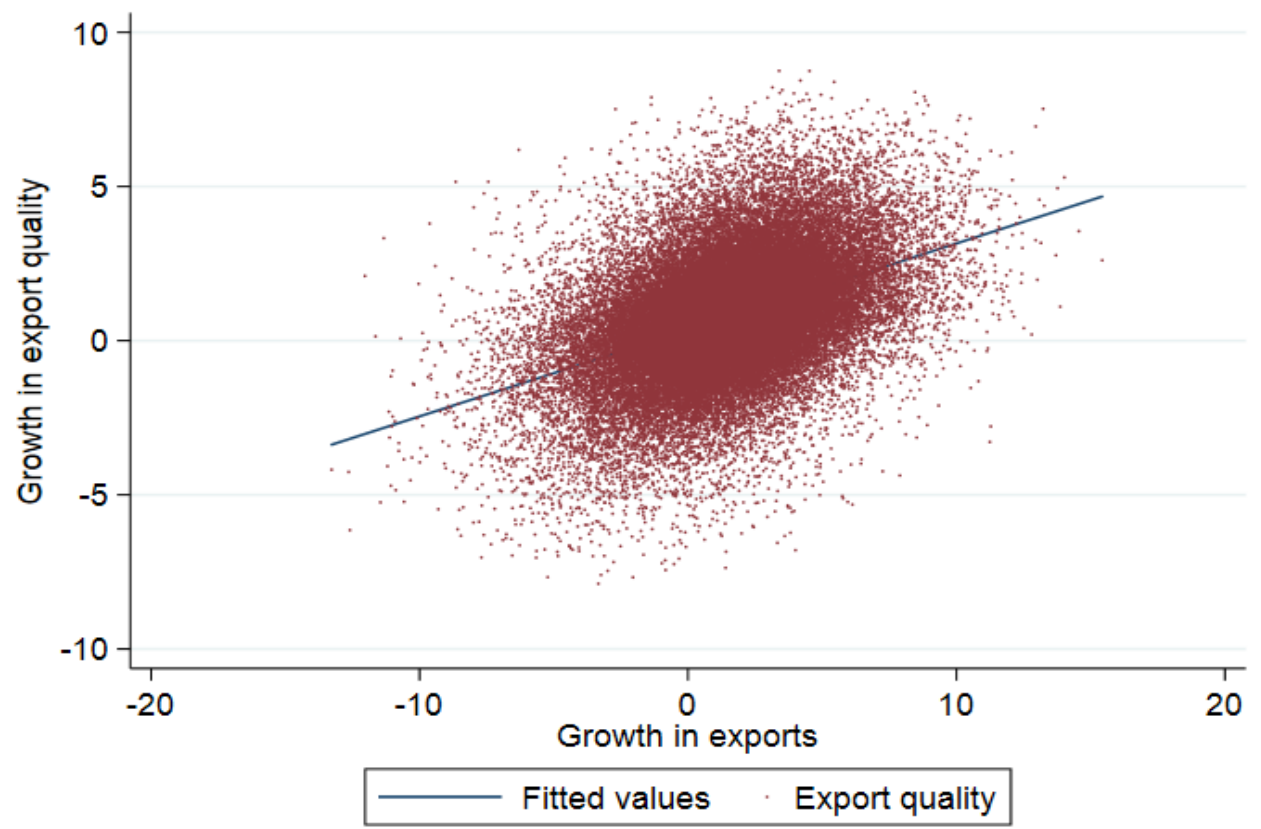

Note: This figure illustrates the relationship between growth in quality and exports at the product level for developed and emerging economies over the periods 1993-2015 and 2000-2014, respectively. 
It can be expected that several factors will contribute to this overall increase in export quality and growth, of which robotics may be just one factor. Roughly linking rising export quality to robot adoption at the industry level suggests already a (small) positive association in developed economies (Figure 4). The (strong) investment in robotics in these countries seem to have contributed to overall increase in product quality - measured at the industry level. The aggregate data suggest that this is not true in emerging economies, with no or even a (small) negative correlation between robotics and the product quality of exports in these countries.

Econometric analysis allows to identify the potential impact of robotics on export quality, thereby accounting for the impacts of other quality determinants. The potential effect of robotics on product quality is assessed at the product as well as the industry level since quality increases at the industry level are taking place along different dimensions; and robotics may impact each of these dimensions. In particular, the empirical analysis distinguishes between changes in the quality of individual products (so-called within product quality change) and the growing importance of higher quality products (the socalled between product quality changes). 
Figure 4. Robot stock and export quality by industry, 1993-2015

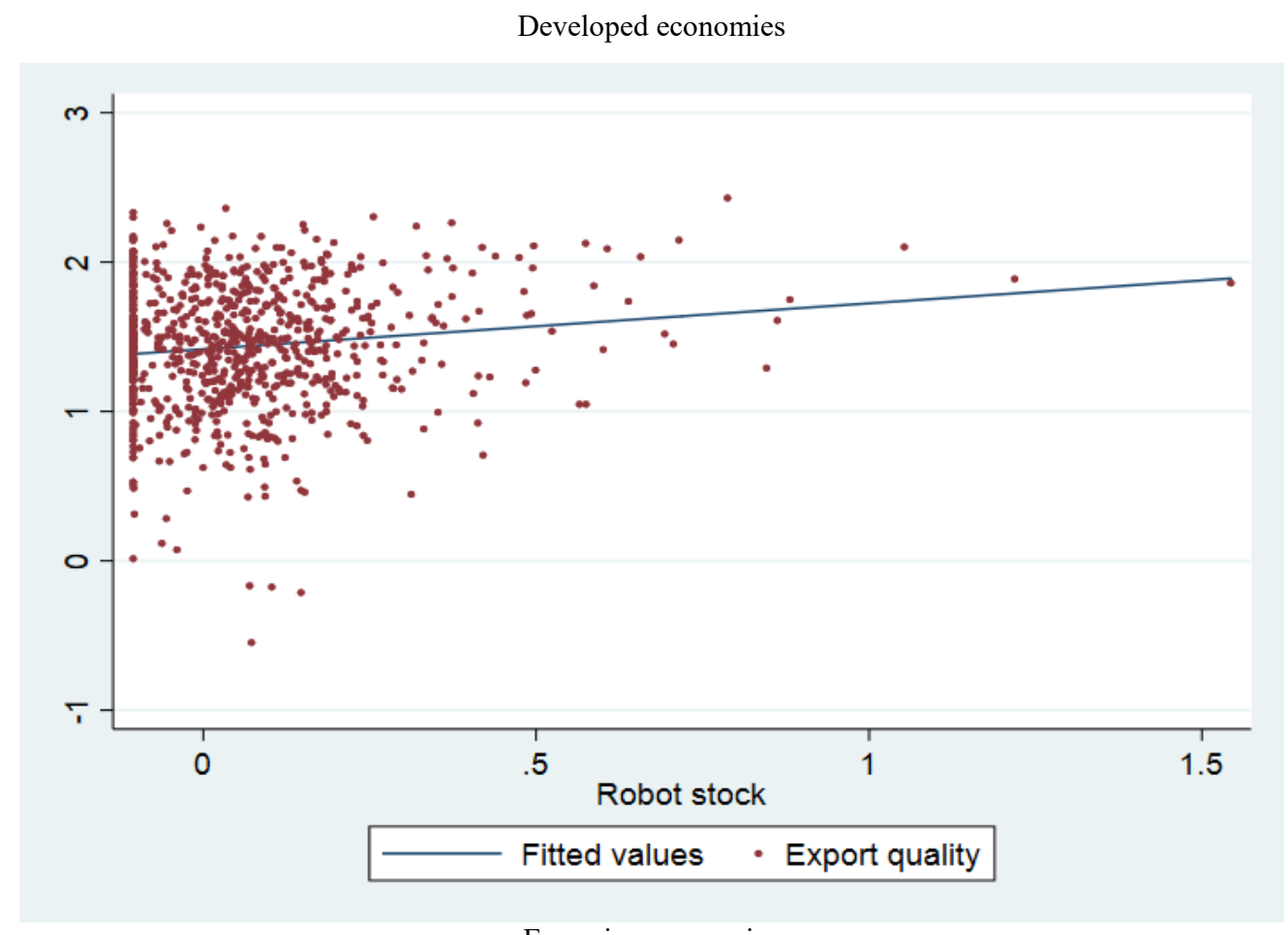

Emerging economies

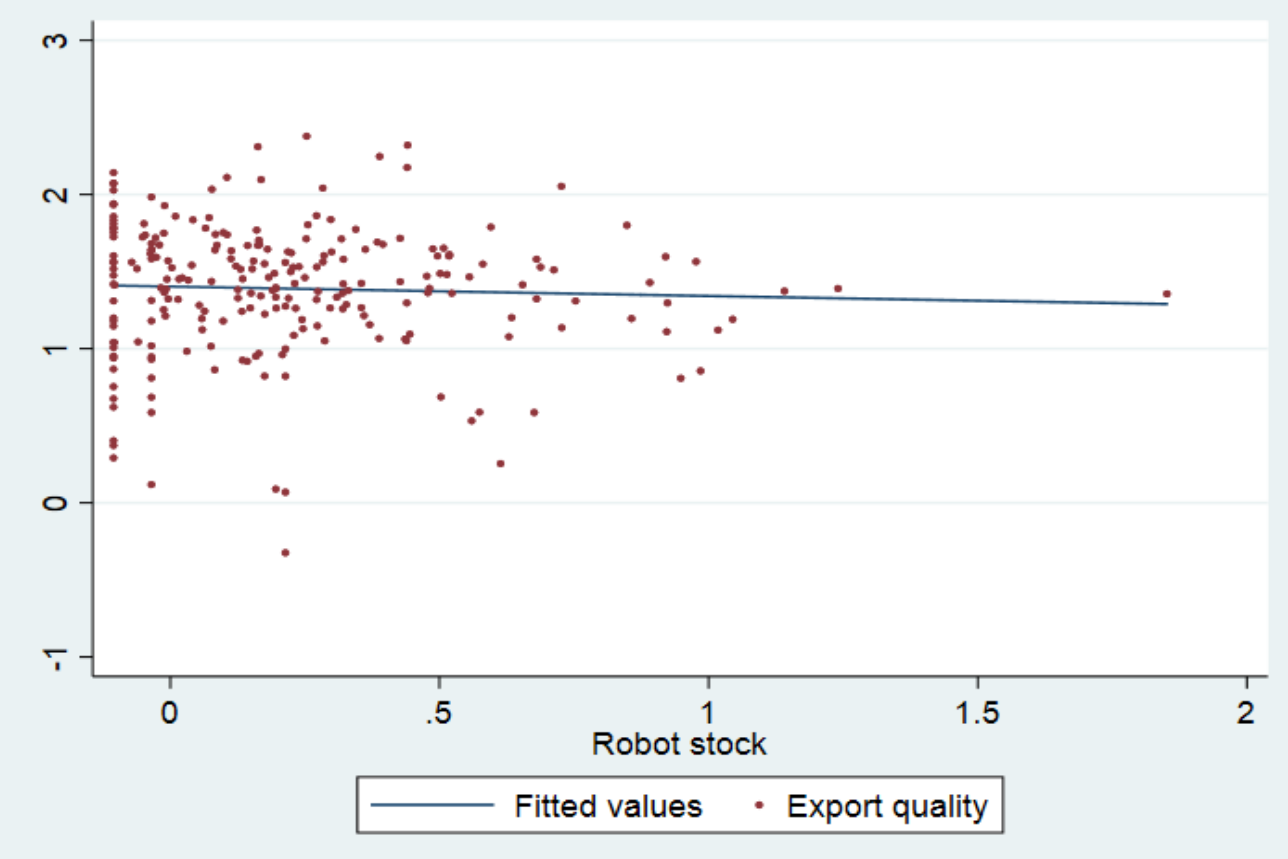

Note: The following figure illustrates the relationship between changes robot stock and export quality amongst highly developed economies. Both robot stock and export quality are expressed as moving averages (over 3 years) at the start and end of the sample period, 1993 and 2015. 


\subsection{Robotics and within-product quality changes}

Empirical evidence has shown that economies not only specialise in industries according to their comparative advantage but also in product varieties within industries. More developed economies are found to produce higher quality goods - because of their relative endowments in skills and capital - while more labour abundant economies manufacture lower quality products (Schott 2004). A first (policy) question addressed in this paper is then to what extent robotics help economies to upgrade their existing output and exports in quality. In doing this, a first analysis looks at so-called within-product quality changes or the effect of robotics on quality in-/decreases of individual products (i.e. at the productpartner combination).

Table 1 presents the results from the reduced form regressions which look at the relationship between growth in robot stock and changes in export quality of individual products (over a three year period) from 1993 to 2015. ${ }^{3}$ The results overall suggest a clear positive effect of industrial robotics on within-product quality ${ }^{4}$ observed in developed as well as emerging economies. The adoption of robotics in the production process is found to result in higher quality output due to greater, precision, lower default rates, etc. as discussed above. With the given datasets and scope of this paper, it is however not possible to assess the exact channel through which robotics lead to greater quality of exports.

Similar to De Backer et al. (2018) who reported important differences for the most recent period, Table 1 also includes separate results for the years after 2010. Somewhat surprisingly, the link between the growth in robots and export quality seems less apparent in this more recent period, particularly for emerging economies. ${ }^{5}$ One potential reason for this may be due to over-investment in some of these regions during the sample period. For developed economies however, the impact of robots is still positive and significant although smaller in size.

Higher levels of production consistency coupled with longer continuous production runs enabled by industrial robotics often means that robotics require higher quality inputs to some extent sourced from abroad. ${ }^{6}$ As such, the paper also assesses whether the use of robotics is reflected in higher quality at the import side (see Table 2). For the group of developed economics, the results show indeed that the adoption of industrial robotics goes together with higher quality intermediates sourced from abroad. No significant effects are observed in the most recent period however, nor for emerging economies. The results also suggest that the effects of robotics are weaker for imports of intermediates than for exports (of all products: final, capital and intermediates), suggesting that the reported effects of robotics on export quality are most likely not solely due to the use of higher quality inputs. 
Table 1. Growth in robot stock on the within-product growth of export quality (exports of all goods)

\begin{tabular}{lcccr}
\hline & HDC & LDC & HDC & LDC \\
\cline { 2 - 5 } Robot stock & \multicolumn{3}{c}{ All years } & \multicolumn{2}{c}{ post 2010 } \\
\cline { 2 - 5 } & $0.008^{* * *}$ & $0.005^{* *}$ & $0.004^{* *}$ & 0.002 \\
& $(0.00)$ & $(0.00)$ & $(0.00)$ & $(0.00)$ \\
R-squared & & & & \\
Observations & 0.103 & 0.178 & 0.065 & 0.155 \\
\hline
\end{tabular}

Note: The following models regresses 3 year growth of exported product quality on 3 year growth of robot stock. The sample periods for HDCs are 1993-2015 and 2010-2015 and for LDCs 2000-2014 and 2010-2014. Robust standard errors in parenthesis. Clustering at the country-sector level. All regressions include exporteryear, product-year and industry fixed effects. Quality refers to estimated Khandelwal (2010) quality measure. Significance: ${ }^{*} \mathrm{p}<0.10, * * \mathrm{p}<0.05, * * * \mathrm{p}<0.01$.

Table 2. Growth in robot stock on the within-product growth of import quality (imports of intermediates)

\begin{tabular}{lcccr}
\hline & HDC & LDC & HDC & LDC \\
\cline { 2 - 6 } & All years & & & post 2010 r \\
Robot stock & $0.014^{*}$ & -0.017 & 0.003 & 0.016 \\
& $(0.01)$ & $(0.02)$ & $(0.01)$ & $(0.02)$ \\
R-squared & 0.153 & & & 0.106 \\
Observations & $11,173,629$ & $2,221,785$ & $4,261,173$ & 0.167 \\
\hline
\end{tabular}

Note: The following models regresses 3 year growth of imported product quality on 3 year growth of robot stock. The sample periods for HDCs are 1993-2015 and 2010-2015 and for LDCs 2000-2014 and 2010-2014. Robust standard errors in parenthesis. Clustering at the country-sector level. All regressions include importeryear, product-year and industry fixed effects. Quality refers to estimated Khandelwal (2010) quality measure. Significance: ${ }^{*} \mathrm{p}<0.10, * * \mathrm{p}<0.05, * * * \mathrm{p}<0.01$.

\subsection{Robotics and between-product quality change}

Within-product quality changes are however only one determinant of the growth in average industry quality. In addition to quality increases of individual products (at the product - partner level), the export portfolio may shift towards higher quality products (even when the quality of all individual products remains the same). Figure 5 shows that these between-product quality changes have been significantly larger than within-product changes in developed as well as emerging economies. Further on, the compositional changes in product quality are overall larger in emerging economies. A second analysis thus relates these compositional changes or between-product changes to the growing investment in robotics across countries and industries. ${ }^{7}$ 
Figure 5. Within- and between-product changes in quality growth by industry, 1993-2015

Developed economies
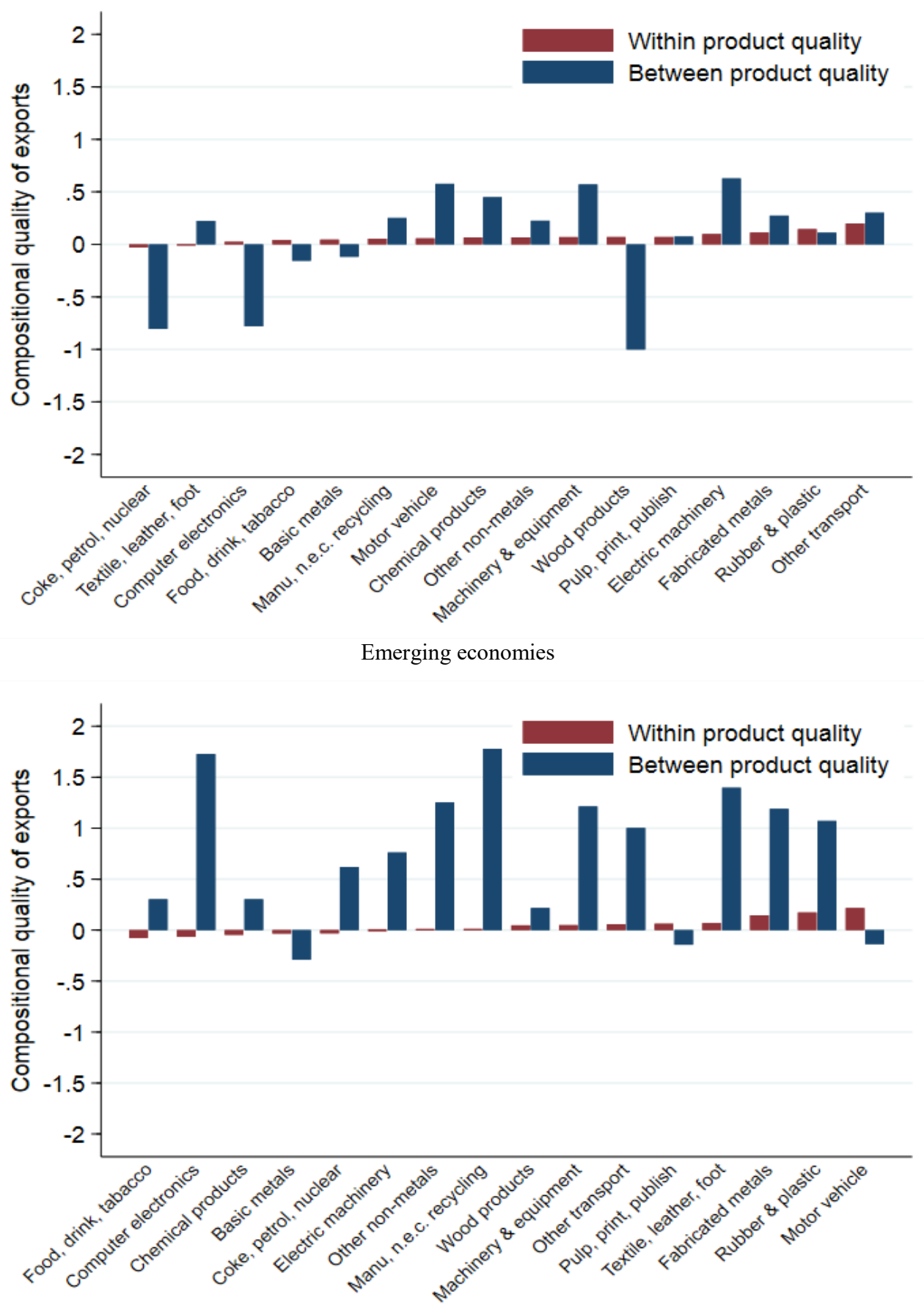

Note: The following figure illustrates changes in within and between product quality for developed and emerging economies over the periods 1993-2015 and 2000-2014, respectively. 
The results in Table 3 shows a positive link between robotics adoption and compositional changes in export quality over time, but only in the case of emerging economies (i.e. also the group that witnessed larger compositional changes in their export portfolio). Greater adoption of robotics in the production process allows these countries to shift their export portfolio to higher quality segments. For developed economies, no such effect is found. Also the results for compositional changes in import quality of intermediates show no impact of robotics on the quality change over time (Table 4).

Table 3. Growth of robot stock on between-product changes of export quality (exports of all goods)

\begin{tabular}{lccccc}
\hline & HDC & LDC & HDC & LDC \\
\cline { 2 - 6 } & \multicolumn{2}{c}{ All years } & \multicolumn{2}{c}{ Post 2010 } \\
\cline { 2 - 6 } Robot stock & 0.002 & $0.025^{* *}$ & -0.025 & 0.022 \\
& $(0.01)$ & $(0.01)$ & $(0.03)$ & $(0.06)$ \\
R-squared & & & & 0.449 & 0.331 \\
Observations & 0.200 & 0.147 & 3,158 & 1,524 \\
\hline
\end{tabular}

Note: The following models regresses changes in export quality composition over time $\mathrm{t}-3$ to $\mathrm{t}$ on changes of robot stock at time t-3. The sample periods for HDCs are 1993-2015 and 2010-2015 and for LDCs 2000-2014 and 2010-2014. Robust standard errors in parenthesis. Clustering at the country-sector level. All regressions include country*sector and year fixed effects. Significance: ${ }^{*} \mathrm{p}<0.10,{ }^{* *} \mathrm{p}<0.05,{ }^{* * *} \mathrm{p}<0.01$.

Table 4. Growth of robot stock on between-product changes of import quality (imports of intermediates)

\begin{tabular}{lrrrrr}
\hline & HDC & LDC & HDC & LDC \\
\cline { 2 - 6 } Robot stock & \multicolumn{3}{c}{ All years } & \multicolumn{3}{c}{ Post 2010 } \\
& -0.016 & -0.022 & -0.024 & 0.059 \\
& $(0.01)$ & $(0.02)$ & $(0.02)$ & $(0.08)$ \\
R-squared & & & & 0.317 & 0.335 \\
Observations & 0.088 & 0.192 & & 7,642 & 705 \\
\hline
\end{tabular}

Note: The following models regresses changes in import quality composition time $\mathrm{t}-3$ to $\mathrm{t}$ on changes of robot stock at time t-3. The sample periods for HDCs are 1993-2015 and 2010-2015 and for LDCs 2000-2014 and 2010-2014. Robust standard errors in parenthesis. Clustering at the country-sector level. All regressions include country*sector and year fixed effects. Significance: ${ }^{*} \mathrm{p}<0.10,{ }^{* *} \mathrm{p}<0.05,{ }^{* * *} \mathrm{p}<0.01$.

\subsection{Robotics and product/geographical concentration}

This section looks at the impact robotics may have on the product and geographical diversification of countries' trade portfolios. It is possible that increasing quality through robotics allows exporters to target new markets and as such diversify their activities geographically. Likewise, robotics may also contribute to product diversification.

Alternatively, the fact that investment in robotics requires higher quality inputs may result in a growing - product as well as geographical - concentration in countries' exports and imports of intermediates. A high(er) dependency on a smaller number of 
suppliers/customers may become a point of interest in the future strategies of companies and/or certain government policies.

To provide insights in the (changes in) product and geographical concentration of trade portfolios, Herfindahl indexes of product and geographical concentration are calculated at the industry-country level. On the export side (See Figure 6), countries appear to have diversified their portfolio geographically between 1993 and 2016: geographical concentration has decreased in basically all industries for both the groups of developed and emerging economies. In addition to targeting more geographical markets, especially emerging economies have also enlarged their product portfolios as reflected in falling product concentration in these countries. For developed economies, the picture is more mixed, with a number of industries also showing falling product concentration, while other industries have become more concentrated in terms of products. 
Figure 6. Changes in geographic and production concentration of exports, by industry, 19932016

Developed economies

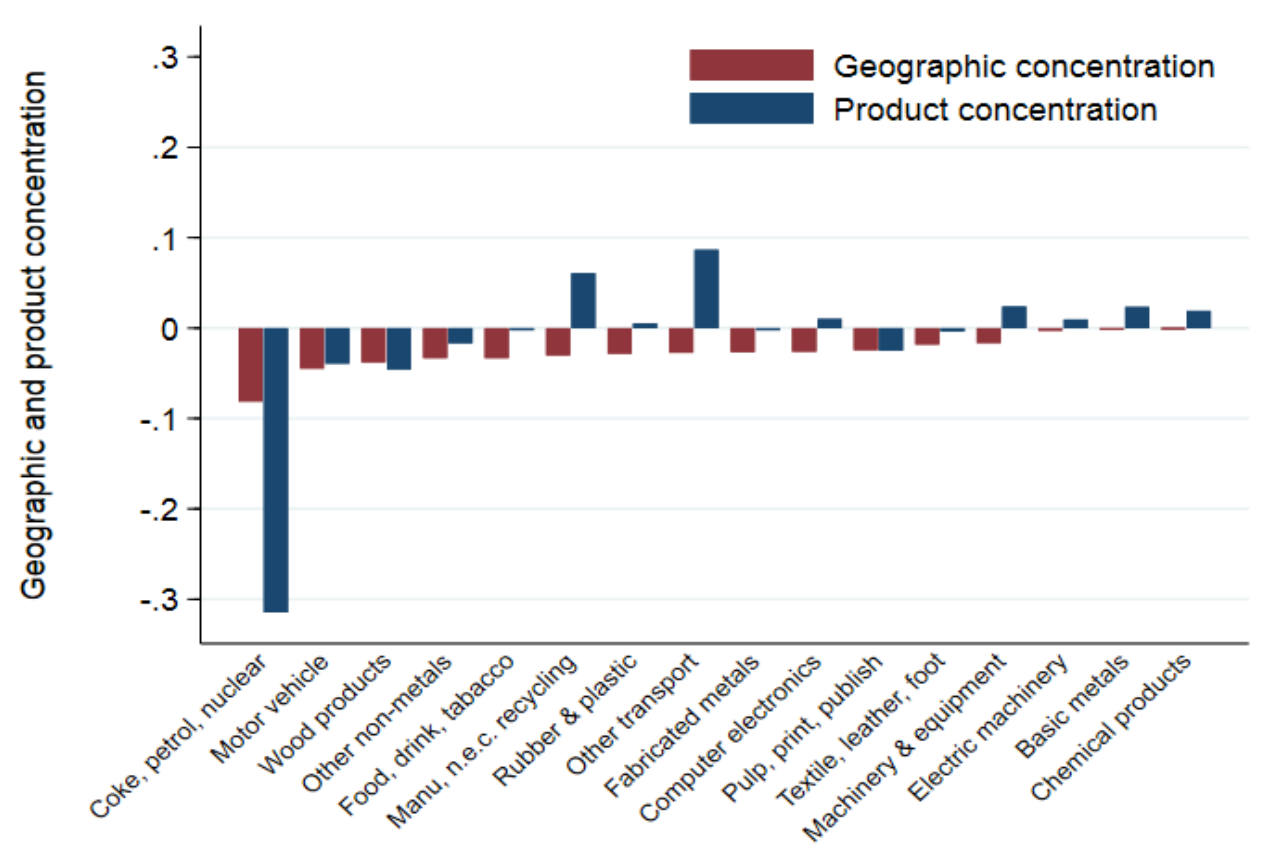

Emerging economies

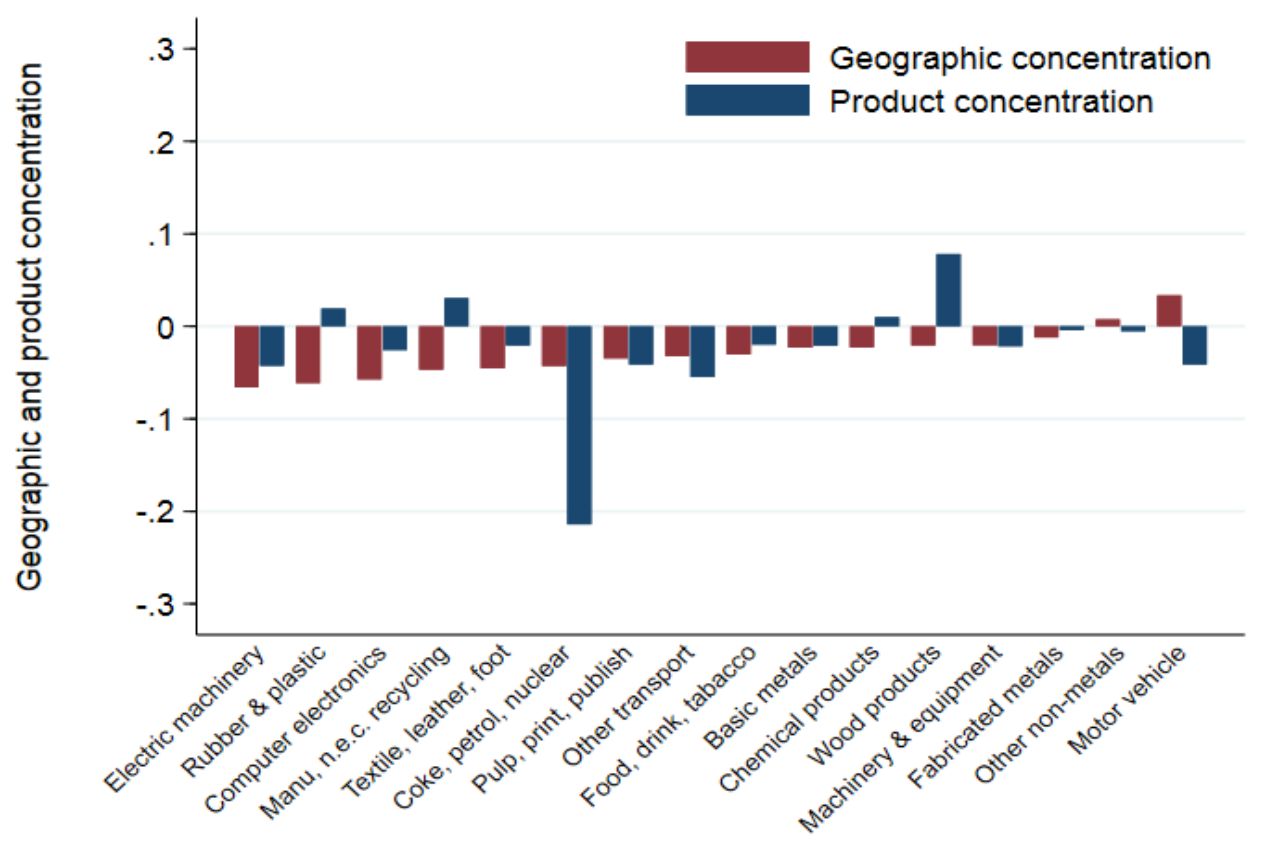

Note: The following figure illustrates the difference in geographic and product concentration of exports between 1993 and 2016 for developed and emerging economies. 


\begin{abstract}
Also on the intermediates import side (See Figure 7), significant differences are evident between developed and emerging economies. Overall, the latter group is observed to source a broader range of inputs from more countries as illustrated by the fact that product as well geographic concentration of imported intermediates has decreased over time. Developed economies seem to have consolidated their international sourcing structure - in terms of products as well as geographical markets - in a number of industries.
\end{abstract}


Figure 7. Changes in geographic and product concentration of intermediate imports, by industry, 1993-2016

Developed economies

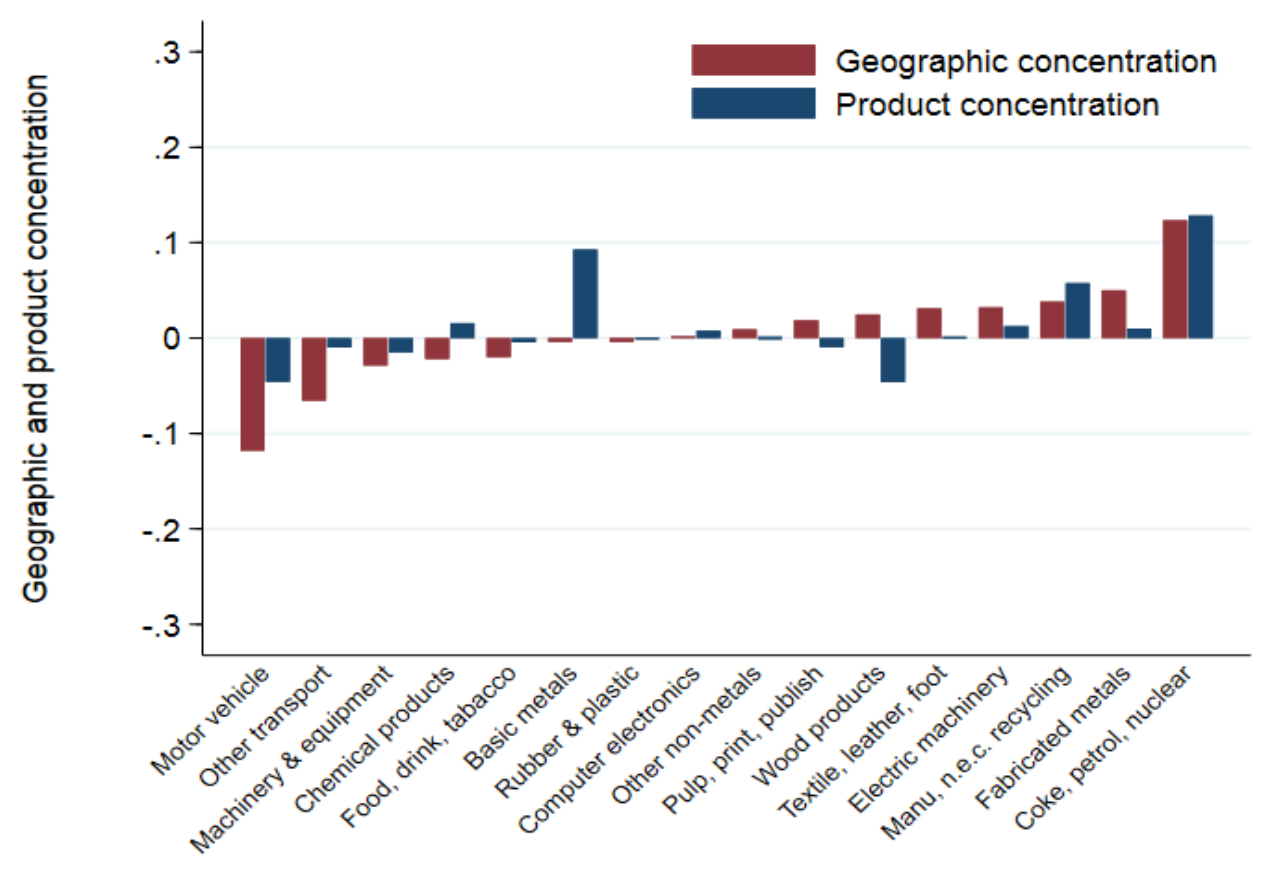

Emerging economies

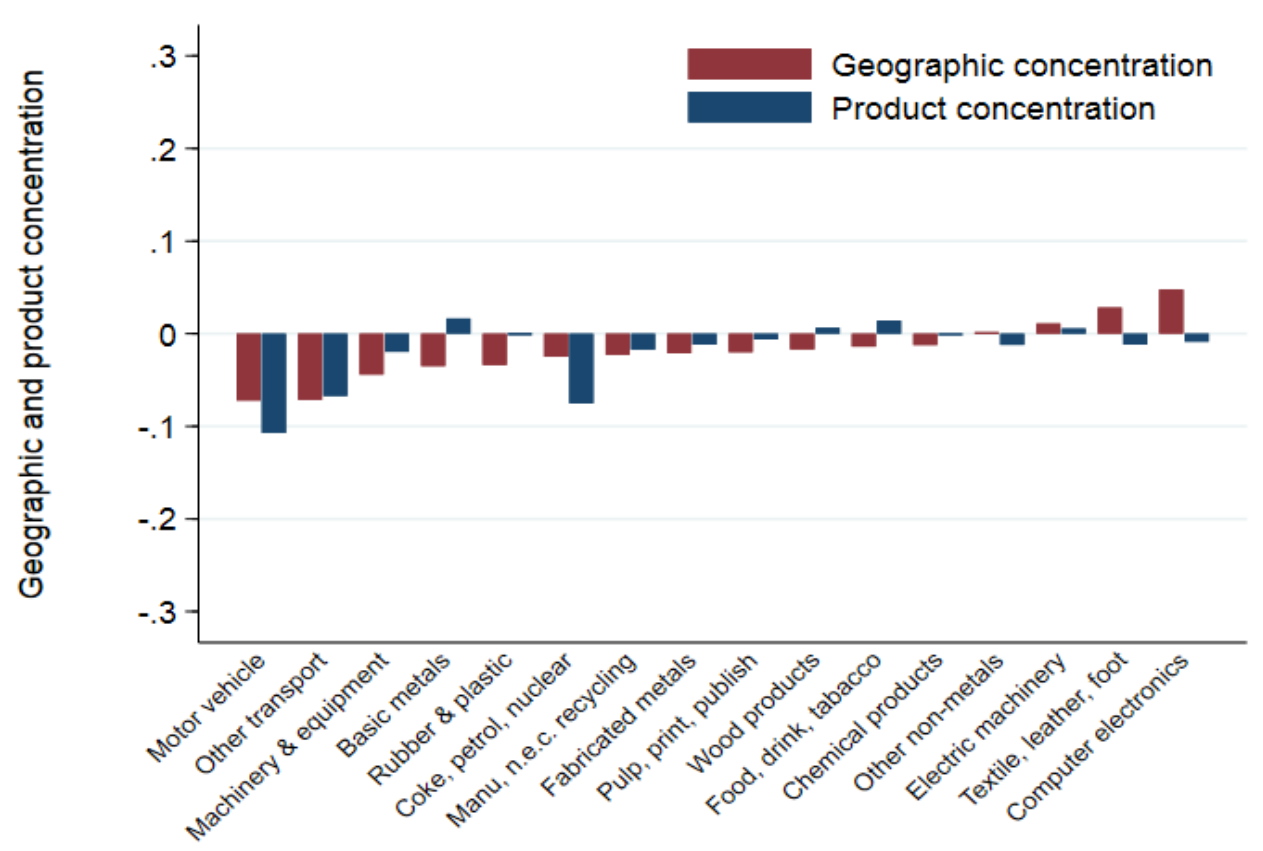

Note: The following figure illustrates the difference in geographic and product concentration of intermediate imports between 1993 and 2016 for developed and emerging economies. 
The changes in product as well as geographical concentration, however, seem not to be linked to the growing investments in robots across industries and countries. The results of the econometric analyses in Tables 7 and 8 do not show an effect of robotics on changes in product and geographical concentration in developed and emerging economies.

Table 5. Growth of robot stock on change in geographic concentration of exports and imports (intermediates)

\begin{tabular}{|c|c|c|c|c|c|c|c|c|}
\hline & \multicolumn{4}{|c|}{ Exports } & \multicolumn{4}{|c|}{ Imports } \\
\hline & $\mathrm{HDC}$ & LDC & $\mathrm{HDC}$ & LDC & $\mathrm{HDC}$ & LDC & $\mathrm{HDC}$ & LDC \\
\hline & \multicolumn{2}{|c|}{ All years } & \multicolumn{2}{|c|}{ Post 2010} & \multicolumn{2}{|c|}{ All years } & \multicolumn{2}{|c|}{ Post 2010} \\
\hline \multirow[t]{2}{*}{ Robot stock } & -0.001 & 0.002 & -0.004 & -0.007 & -0.001 & 0.001 & 0.001 & 0.001 \\
\hline & $(0.00)$ & $(0.00)$ & $(0.00)$ & $(0.00)$ & $(0.00)$ & $(0.00)$ & $(0.00)$ & $(0.00)$ \\
\hline Observations & 11,064 & 5,007 & 3,854 & 1,823 & 10,696 & 4,915 & 3,671 & 1,736 \\
\hline
\end{tabular}

Note: The following models regress changes of geographic concentration of exports and imports over time $\mathrm{t}-3$ to $t$ on changes of robot stock at time t-3 in a truncated regression framework. Sample period for developed and emerging economies is 1993-2016 and 2010-2016. Robust standard errors in parenthesis. Clustering at the country-sector level. All regressions include country*sector and year fixed effects. Significance: * $\mathrm{p}<0.10,{ }^{* *}$ $\mathrm{p}<0.05, * * * \mathrm{p}<0.01$.

Table 6. Growth of robot stock on change in product concentration of exports and imports (intermediates)

\begin{tabular}{|c|c|c|c|c|c|c|c|c|}
\hline & \multicolumn{4}{|c|}{ Exports } & \multicolumn{4}{|c|}{ Imports } \\
\hline & $\mathrm{HDC}$ & LDC & $\mathrm{HDC}$ & LDC & HDC & LDC & $\mathrm{HDC}$ & LDC \\
\hline & \multicolumn{2}{|c|}{ All years } & \multicolumn{2}{|c|}{ Post 2010} & \multicolumn{2}{|c|}{ All years } & \multicolumn{2}{|c|}{ Post 2010} \\
\hline \multirow[t]{2}{*}{ Robot stock } & $-0.008^{*}$ & 0.003 & 0.000 & 0.009 & 0.000 & -0.003 & -0.002 & 0.002 \\
\hline & $(0.00)$ & $(0.01)$ & $(0.01)$ & $(0.02)$ & $(0.00)$ & $(0.00)$ & $(0.00)$ & $(0.01)$ \\
\hline Observations & 9,258 & 3,995 & 3,239 & 1,452 & 10,696 & 4,915 & 3,671 & 1,736 \\
\hline
\end{tabular}

Note: The following models regress changes of product concentration of exports and imports over time $\mathrm{t}-3$ to $t$ on changes of robot stock at time t-3 in a truncated regression framework. Sample period for developed and emerging economies is 1993-2016 and 2010-2016. Robust standard errors in parenthesis. Clustering at the country-sector level. All regressions include country*sector and year fixed effects. Significance: ${ }^{*} \mathrm{p}<0.10,{ }^{* *}$ $\mathrm{p}<0.05, * * * \mathrm{p}<0.01$ 


\section{Policy insights}

This paper adds to the limited but rapidly growing literature on the economic effects of robotics and their implications for policy. It looks particularly at the possible effects of robotics adoption on the quality of the exports (of all goods) and intermediates imports. As such, this paper offers complementary insights to our previous paper (De Backer et al.,2018) which showed the negative effect of robotics on GVC trade, particularly with respect to the international sourcing of intermediates.

Overall, the results in this paper do not yet show a large impact of robotics on product quality. The same qualifications as in De Backer et al. (2018) apply to the empirical analysis in this paper: the partial information on robotics (at the industry level, only the number of robots, no information on the quality of robotics); and the short time period to assess the effects of robotics due to the relative recent uptake in robotics investments across a growing number of countries.

The results in this paper suggest that the effect of robotics on product quality takes place along different dimensions in developed and emerging economies. In developed economies, robotics give especially rise to within-product quality changes, i.e. quality enhancement of individual products. Quality increases are also observed on the import side of intermediates, indicating that the adoption of robotics requires also higher quality inputs. Robotics however do not result in major compositional changes in developed economies' export and import portfolios.

In emerging economies, quality changes are driven by within-product as well as between product changes. In addition to quality enhancement of existing products, robotics is also associated with a restructuring of countries' trade portfolios towards higher quality products. Interestingly, the growth in quality on the export side is not mirrored on the import side, meaning that in contrast to developed economies the requirement for higher quality inputs is less pressing in emerging economies.

In contrast to our previous paper, which showed that the effects of robotics on offshoring were very recent, i.e. most observable in more recent years, the results in this paper seem to suggest that the quality effects of robotics are less prominent (and non-existent) in recent years. It is not very clear what the underlying reason for this result, but it may be due to the fact that the quality effects of robotics may take some to materialise and/ or some regions may actually be over investing in industrial robotics.

Altogether, the results show that robotics - similar to De Backer et al. (2018) - may help economies to safeguard/regain competitiveness in manufacturing industries. Beneficial effects of robotics are observed in developed economies as well as in emerging economies. Building further on this argument, while it has been documented that robotics may save on labour costs and hence improve productivity and competitiveness in labour-intensive industries, the results demonstrate another avenue for companies to improve their performance via robotics through increased product quality. This paper demonstrates that the adoption of robotics in the production process may result in important quality gains in terms of accuracy, complexity, minimal error, etc.

As such, the paper offers evidence for the potential of robotics to help companies and countries upgrade their GVC activities. The positive effects of robotics on within-product (in developed economies) as well as between-product (in emerging economies) quality 
changes directly underline the importance of robotics for product upgrading. The churning of new and old product varieties linked to robotics further underscores the potential of robotics for product upgrading but also value chain upgrading, since this churning has been demonstrated to go together - or actually driven by - changes in trade partners. The potential of robotics for process and functional upgrading is likely more indirect as it can be envisaged that robotics allows companies to improve and change their activities within specific GVCs.

While not shown in this paper, it has been documented in previous work that the successful adoption of robotics is dependent on investment in complementary assets. Human skills have been demonstrated to be one complementary asset as robots today still need to be intensively programmed before they can undertake their automated activity. Education and continuous training in IT skills are thus a prerequisite for economies shifting their production technologies towards higher automation.

However, as robotics become more self-learning and artificial intelligence is adopted more prominently, some argue that the importance of human skills may decrease over time. Selfprogramming robots will reduce the human capital barrier for adopting industrial robotics since they do not require the complexity of individualised coding that traditional robots require. Technological advances in self-programmable robots and incentives to adopt these machines will make it easier and more cost-effective for smaller firms to implement appropriate manufacturing technologies to enhance performance and product quality.

Other complementary assets include communication technologies and data networks. Indeed, robotics are only one factor in the digital transformation of production. OECD (2017) has distinguished three broader technologies underpinning the digitalisation of production: the Internet of Things (IoT) including robotics, which enables the interconnection of machines, inventories and supply chains; big data and embedded software, which allow for the analysis of the huge volumes of digital data generated by these objects; and additive manufacturing and machine to machine learning.

OECD as well as emerging economies are strongly promoting and supporting the digitalisation of their economies. De Backer et al. (2018) described for a number of countries how and to what extent research, development and adoption of robotics is stimulated frequently via direct government support. The importance of complementary assets underlines the need for a broader policy to be successful. One reason why some countries seem to benefit less from robotics may be the lack of (support for) investment in complementary assets. But again, more research based on more recent and detailed data is needed to be able to confirm this.

Given the importance of good international sourcing of high quality intermediates, this paper underscores indirectly the importance of open borders and trade networks. Tariff and non-tariff barriers at national borders may impede the beneficial effects of robotics when they limit the international sourcing of high quality intermediates. The results are in line with previous studies showing the positive effects of liberalisation as imports of intermediates can mean less expensive or - as shown in this paper - higher quality products. 


\section{Annex A. The data}

\section{Data}

This report pools together data from five different sources. Information on industrial robotics use comes from the International Federation of Robotics (see De Backer et al (2018) for a discussion on the data as well as descriptive statistics). Product level data on exports and imports comes from the OECD Bilateral Trade Database by Industry and Enduse. Moreover, additional information on country-partner trade characteristics and industry level controls are derived from the Centre d'Études Prospectives et d'Informations Internationales, the OECD Structural Analysis Database and the World Input Output Database.

In order to identify the potential channels of upgrading, the work assesses the relationship between robot use and the quality of product exports and imports by industries within countries overtime. Traditionally in the trade literature, unit prices (which is simply export (import) values over quantities) are used as measures of quality (See Schott 2004: Hallak 2006). These measures however may be influenced by a range of factors other than quality itself. Asides for quality changes, unit prices may actually reflect the pricing policy of a business, be influenced by quality adjusted price trends, and/or the composition of products produced within HS classification may be heterogeneous across exporters (Henn et al 2015). Moreover, all of these factors are likely to be influenced by macro-economic shocks, such as the great recession which occurred during our sample period.

As a result, the main quality estimate used in this paper comes from Khandelwal (2010). ${ }^{8}$ This quality estimate is calculated within a demand equation based on the assumption that higher quality products (conditional on prices) should occupy a larger market share in the destination country. ${ }^{9}$

These measures of trade quality can be derived from OECD Bilateral Trade Database by Industry and End-use H.S. 6 digit data and then matched to countries and sectors with the robotics data overtime. This allows one to examine whether robot use is correlated with an increase in the quality of existing exported (imported) goods and/or whether robot use induces firms to replace pre-existing goods with new varieties. An additional benefit to the data is the length of its time series, providing us with trade data up to 2015.

The empirical analysis of this paper relies on separate samples based on the level of development of the economy. Ideally one would rely on a single dataset of highly developed and emerging economies to assess whether the effects of robotics on trade exhibits statistically different effects across these two groups. Data requirements for the quality estimate however prevent us from having the same time coverage for all countries. ${ }^{10}$

The sample of highly developed economies contains data on 5,624 products amongst 33 countries and 16 industries over the period of 1993-2015. For emerging economies data provides information on 16 economies, 5,621 products and 16 sectors from 2000 to 2014. 


\section{Empirical strategy}

\section{Quality of trade}

The baseline estimates assess the link between robotics and trade quality illustrated in Equation 1. $\Delta$ trade $_{\text {pist }}$, represents change in the quality of exports (imports) of product $p$, for country $i$, within sector $s$, over time $t-3$ to time $t$, (3 year intervals). $\Delta$ robot $_{\text {ist }}$ reflects the change in robot stock in country $i$, for sector $s$, over the time period. $\chi_{i s t}$ signifies additional fixed effects included in all product level regressions, country-year, product-year and industry and $\mu_{i s t}$ represents the error term. As discussed previously, the quality estimate used in this paper is derived from Khandelwal (2010).

$$
\Delta \text { trade }_{\text {pist }}=\alpha_{0}+\alpha_{1} \Delta \text { robot }_{i s t}+\chi_{i s t}+\mu_{i s t}
$$

\section{Compositional quality measure}

In order to understand the extent to which the production of higher quality products are becoming more prominent within industries overtime, the paper estimates a compositional quality average to be included as the dependent variable. The objective of this estimation is to see whether the use of robots is related to higher quality products being more prominent within an industry overtime. The weights reflect the export value of product $p$ from country $i$ to partner $j$ at time $t$ divided by all exports from county $i$ and sector $s$ across all products and partners in time $t$. These weights are used to calculate the average quality at the country-sector level (see Equation 2). After which we then take the difference of the contemporaneous average with the lagged (three year) quality average with the quality average calculated with the change in quality measures (over three years) and lagged weights (three years). This is then regressed on changes in year t-3 robot stock in an OLS frame work that includes country*industry and year fixed effects (see Equation 3). A positive relationship with change in robot stock would therefore suggest that higher quality products are taking a more important role amongst the composition of goods traded by sectors within countries overtime.

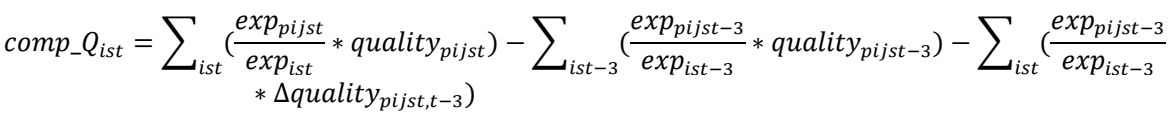

$$
\Delta \operatorname{comp}_{-} Q_{i s t}=\alpha_{0}+\alpha_{1} \Delta \text { robot }_{i s t}+\chi_{i s t}+\mu_{i s t}
$$

\section{Product and geographic concentration}

The final section of the paper estimates the extent to which changes in robot stock are linked to both greater geographic and product concentration of exports and imports 
overtime. A standard Herdindahl index is used as a measure for concentration illustrated in Equation 4 and Equation 5. The first term represents the product concentration measure which is the value of a product $p$ from country $i$ in sector $s$, to all partners over the value of trade from country $i$ sector $s$ in time $t$ to the power of two and summed over country, industry and year. The geographic concentration measure is then the value of trade between country $i$ and sector $s$ to partner $j$ of all products over the value of trade of country $i$ sector $s$ in time $t$ to the power of two and summed over country, industry and year. The measure of concentration (either product exports (imports) or geographic exports (imports)) and robot stock is then estimated in Equation 6 which regresses changes in concentration over time $t-3$ to $t$ on changes in robot stock in $t-3$ and includes the same fixed effects as Equation 3, country-industry and year.

$$
\begin{aligned}
& c o n \_p_{i s t}=\sum_{i s t} \frac{\text { trade_} v_{p i s t}{ }^{2}}{\text { trade_ }_{\text {ist }}} \\
& c o n \_g_{i s t}=\sum_{i s t} \frac{{ }_{t r a d e \_} v_{i j s t}{ }^{2}}{\text { trade_}_{-} v_{i s t}}
\end{aligned}
$$

$\Delta c o n \_p_{i s t}=\alpha_{0}+\alpha_{1} \Delta$ robot $_{i s t}+\chi_{i s t}+\mu_{i s t}$ 
Annex B. Economy and industry coverage

Table A B.1. Economy coverage

\begin{tabular}{|c|c|c|}
\hline Count & $\begin{array}{l}\text { Highly Developed } \\
\text { Economies }\end{array}$ & $\begin{array}{c}\text { Less Developed } \\
\text { Economies }\end{array}$ \\
\hline 1 & AUS & ARG \\
\hline 2 & AUT & BGR \\
\hline 3 & BEL & BRA \\
\hline 4 & $\mathrm{CHE}$ & $\mathrm{CHN}$ \\
\hline 5 & $\mathrm{CHL}$ & HRV \\
\hline 6 & CZE & IDN \\
\hline 7 & DEU & IND \\
\hline 8 & DNK & MLT \\
\hline 9 & ESP & MYS \\
\hline 10 & EST & PHL \\
\hline 11 & FIN & ROU \\
\hline 12 & FRA & RUS \\
\hline 13 & GBR & THA \\
\hline 14 & GRC & TUR \\
\hline 15 & HKG & VNM \\
\hline 16 & HUN & ZAF \\
\hline 17 & IRL & \\
\hline 18 & ISR & \\
\hline 19 & ITA & \\
\hline 20 & JPN & \\
\hline 21 & KOR & \\
\hline 22 & LTU & \\
\hline 23 & NLD & \\
\hline 24 & NOR & \\
\hline 25 & NZL & \\
\hline 26 & POL & \\
\hline 27 & PRT & \\
\hline 28 & SGP & \\
\hline 29 & SVK & \\
\hline 30 & SVN & \\
\hline 31 & SWE & \\
\hline 32 & TWN & \\
\hline 33 & USA & \\
\hline
\end{tabular}

Note: Emerging economies are defined using the World Bank classification in 1995. 
Table A B.2. Industrial coverage

\begin{tabular}{|c|c|}
\hline Classification & Description \\
\hline $10 t 12$ & Food products, beverages and Tabaco \\
\hline $13 \mathrm{t} 15$ & Textiles, leather, footwear \\
\hline 16 & Wood, products of word and cork \\
\hline $17 t 18$ & Pulp, paper products, printing and publishing \\
\hline 19 & Manufacture of coke and refined petroleum products \\
\hline $20 t 21$ & Chemicals, chemical products and pharmaceuticals \\
\hline 22 & Manufacture of rubber and plastics products \\
\hline 23 & Manufacture of other non-metallic mineral product \\
\hline 24 & Manufacture of basic metals \\
\hline 25 & $\begin{array}{l}\text { Manufacture of fabricated metal products, except machinery } \\
\text { and equipment }\end{array}$ \\
\hline 26 & Manufacture of computer, electronic and optical products \\
\hline 27 & Manufacture of electrical equipment \\
\hline 28 & Manufacture of machinery and equipment n.e.c. \\
\hline 29 & Manufacture of motor vehicles, trailers and semi-trailers \\
\hline 30 & Manufacture of other transport equipment \\
\hline $31 \mathrm{t} 33$ & Manufacturing, n.e.c; recycling \\
\hline
\end{tabular}

Note: Industrial classification is ISIC rev4. 


\section{Notes}

Industrial robot refers to ISO classification 8373:2012: "an automatically controlled, reprogrammable, multipurpose manipulator programmable in three or more axes, which can be fixed in place or mobile for use in industrial automation applications" (IFR 2016).

Currently self-programing robots only make up a small proportion of machines used in the economy and tend to be targeted more towards SMEs (IFR 2017).

As a robustness test, regressions were also carried out across different temporal periods (including one, two, three, four and five year periods). These robustness checks find consistent results.

These results, particularly for the sample of highly developed economies are robust to the inclusion of a number of fixed effects (country-year, product-year and industry) which the trade literature suggests are important dimensions to control for (see Khandelwal 2013).

Because of data availability, the sample period for emerging economies is however shorter (i.e. years 2015 are not included).

No information - at the product level - is available about the use of domestic intermediates, hence the focus is on imported intermediates. De Backer et al. (2018) showed however that robotics may reduce the international sourcing of intermediates.

The between-product changes in quality at the industry level are calculated as the difference between the growth in average industry quality (see Figure 1) minus the average within-product quality change (i.e. by keeping the share of individual products in total industry exports constant). For a detailed description of the compositional quality measure please refer to the Annex.

Please refer to Khandelwal (2010) for a theoretical and an empirical discussion on this quality measure.

A recent measure by Feenstra and Romalis (2014) takes into account demand and supply side factors that influence quality. However due to a number of data constraints, this paper relies predominately on the Khandelwal (2010).

For example, import penetration measures at the country industry level are used to estimate the Khandelwal quality measure. The data is derived both from STAN and WIOD, thus quality measures for emerging economies is only available up to 2014 . 


\section{References}

Agapakis, J. et al. (1990), "Vision-Aided Robotic Welding: An Approach and a Flexible Implementation", The International Journal of Robotics Research, Vol. 9/5, pp. $17-34$.

Amiti, M., and A. Khandelwal (2013), "Import Competition and Quality Upgrading", Review of Economics and Statistics, Vol. 95/2, pp. 476-490.

Argote, L. and Goodman, P.S. (1986), "The Organizational Implications of Robotics", Managing Technological Innovation, Davis, D.D. (Ed), Jossey-Bass, San Francisco, pp. 127-153.

Ayres, Robert U., and Steven M. Miller. (1983), "Robotic Realities: Near-Term Prospects and Problems", The Annals of the American Academy of Political and Social Science, Vol. 470/1, pp. 28-55.

Bas, M., and V. Strauss-Kahn. (2015), "Input-Trade Liberalization, Export Prices and Quality Upgrading”, Journal of International Economics, Vol. 95/2, pp. 250-262.

Andrew B. Bernard \& J. Bradford Jensen, 2000. "Exporting and Productivity," Working Papers 00-07, Center for Economic Studies, U.S. Census Bureau.

Bernard, A. B., I. Van Beveren \& H. Vandenbussche, 2014. "Multi-Product Exporters and the Margins of Trade," The Japanese Economic Review, Japanese Economic Association, vol. 65(2), pages 142-157, June.

Bogue, R. (2013), "Robotic Vision Boosts Automotive Industry Quality and Productivity", Industrial Robot: An International Journal, Vol. 40/5, pp. 415-419.

Buxey, G. (1991), “The Nexus between CAD-CAM and Quality”, International Journal of Operations \& Production Management, Vol. 11/10, pp. 19-32.

Crozet, M., K. Head and T. Mayer (2011), "Quality Sorting and Trade: Firm-Level Evidence for French Wine”, The Review of Economic Studies, Vol. 79/2, pp. 609644.

De Backer, K. et al. (2018), "Industrial robotics and the global organisation of production", OECD Science, Technology and Industry Working Papers, No. 2018/03, OECD Publishing, Paris, http://dx.doi.org/10.1787/dd98ff58-en. 
Deloitte (2017), "Industry 4.0, Smart Factory, and Connected Manufacturing", ", Accessed January 30, 2018.

https://www2.deloitte.com/insights/us/en/focus/industry-4-0/smart-factoryconnected-manufacturing.html.

European Commission (2014), "CORDIS : Projects and Results : Plug-and-Produce COmponents and METhods for Adaptive Control of Industrial Robots Enabling Cost Effective, High Precision Manufacturing in Factories of the Future", https://cordis.europa.eu/project/rcn/95706 en.html.

Fabricator. (n.d), "Robotic Welding: Don't Forget the Consumables", Accessed February 22, 2018. https://www.thefabricator.com/article/arcwelding/roboticwelding-donat-forget-the-consumables.

Feenstra, R., and J. Romalis (2014), "International Prices and Endogenous Quality", The Quarterly Journal of Economics, Vol. 129/2, pp. 477-527.

Gates, D (2013), "Painting Robots Speed Production of Boeing 777s", USA Today, https://www.usatoday.com/story/todayinthesky/2013/06/03/painting-robots-speedproduction-of-boeing- $777 \mathrm{~s} / 2384009 /$.

Graetz, G., and G. Michaels (2015), "Robots at Work”, CEP Discussion Paper, No. 1335.

Groover, M., and E. Zimmers (1983), CAD/CAM: Computer-Aided Design and Manufacturing. Pearson Education.

Grossman, G., and E. Helpman (1991), "Quality Ladders and Product Cycles”, The Quarterly Journal of Economics, Vol. 106/2, pp. 557-586.

Guest, R. (1984), Robotics, the Human Dimension. Work in America Institute, Incorporated.

Gunasekaran, S. (1996), "Computer Vision Technology for Food Quality Assurance”, Trends in Food Science \& Technology, Vol. 7/8, pp. 245-256.

Hallak, J., and J. Sivadasan (2013), "Product and Process Productivity: Implications for Quality Choice and Conditional Exporter Premia", Journal of International Economics, Vol. 91/1, pp. 53-67.

Hallak, J. (2010), "A Product-Quality View of the Linder Hypothesis", The Review of Economics and Statistics, Vol. 92/3, pp. 453-466.

Hallak, J. (2006), "Product Quality and the Direction of Trade", Journal of International Economics, Vol. 68/1, pp. 238-265. 
Henn, C., C. Papageorgiou, J. Romero, and N. Spatafora (2017), "Export Quality in Advanced and Developing Economies: Evidence from a New Data Set", WTO Working Paper, ERSD-2015-02

Herakovic, N. et al. (2011), "A Machine-Vision System for Automated Quality Control of Welded Rings", Machine Vision and Applications, Vol. 22/6, pp. 967-81. https://doi.org/10.1007/s00138-010-0293-9.

Herakovic N. (2010), "Robot vision in industrial assembly and quality control processes", In: Ude A, editor. Robot vision. InTech; 2010. p. 501-34.

Hidalgo, C. et al. (2007), "The Product Space Conditions the Development of Nations", Science, Vol. 317/5837, pp. 482-87. https://doi.org/10.1126/science.1144581.

Hirschman, A. (1958), “The Strategy of Economic Development”, New Haven, Conn.: Yale University Press

Hummels, D., and P. Klenow. (2005), “The Variety and Quality of a Nation's Exports”, American Economic Review, Vol. 95/3, pp. 704-723.

IMF (2017), “Advanced Economies: IMF Key Issues”, 2017. http://www.imf.org/external/np/exr/key/advanced.htm.

International Federation of Robotics (2017), Economic implications of industrial robotics, In person interview, December $12^{\text {th }} 2017$.

International Federation of Robotics (2016), "World Robotics Report 2016”, IFR Press Release. Frankfurt.

Khandelwal, A. (2010), "The Long and Short (of) Quality Ladders", The Review of Economic Studies, Vol. 77/4, pp. 1450-1476.

Korean Institute for Robot Industry Advancement (2018), "Korea Robot Industry Promotion Agency Key Achievements", https://www.kiria.org/index.9is?contentUid=ff8080815c9a6cc2015e0da45bcd2e29.

Manova, K., and Z. Zhang. (2012), "Export Prices across Firms and Destinations", The Quarterly Journal of Economics, Vol. 127/1, pp. 379-436.

Michalos, G. et al. (2016), "Performance Assessment of Production Systems with Mobile Robots", Procedia CIRP, Vol. 41, pp. 195-200.

Michalos, G., S. Makris, and G. Chryssolouris. (2015), "The New Assembly System Paradigm", International Journal of Computer Integrated Manufacturing, Vol. 28/12, pp. 1252-1261. 
Mikusz, M., and A. Csiszar (2015), "CPS Platform Approach to Industrial Robots: State of the Practice, Potentials, Future Research Directions", In PACIS proceedings, 176.

Milgrom, P., and J. Roberts. (1990), “The Economics of Modern Manufacturing: Technology, Strategy, and Organization”, The American Economic Review, Vol. 80/3, pp. 511-28.

OECD (2017), "Going Digital: Making the Transformation Work for Growth and WellBeing, Document Prepared for the MCM 2017 Meeting,”, OECD publishing, Paris. https://www.oecd.org/mcm/documents/C-MIN-2017-4\%20EN.pdf.

Pricewaterhouse Coopers (2014), "The New Hire: How a New Generation of Robots Is Transforming Manufacturing”, https://www.pwc.com/us/en/industries/industrialproducts/library/robotic-trends-changing-manufacturing.html

Rosenstein-Rodan, P. (1943), "Problems of Industrialisation of Eastern and SouthEastern Europe", The Economic Journal, Vol. 53/210, pp. 202-211.

Schott, P. (2004), "Across-Product versus within-Product Specialization in International Trade", The Quarterly Journal of Economics, Vol. 119/2, pp. 647-678.

Singh, C. B., and D. Jayas. (2013), "5 - Optical Sensors and Online Spectroscopy for Automated Quality and Safety Inspection of Food Products", In Robotics and Automation in the Food Industry, edited by Darwin G. Caldwell, pp. 111-29. Woodhead Publishing Series in Food Science, Technology and Nutrition.

Tilley, J. (2017), "Automation, Robotics, and the Factory of the Future" McKinsey \& Company, https://www.mckinsey.com/business-functions/operations/ourinsights/automation-robotics-and-the-factory-of-the-future.

Valente, A., S. Baraldo, and E. Carpanzano. (2017), "Smooth Trajectory Generation for Industrial Robots Performing High Precision Assembly Processes", CIRP Annals Vol. 66/1, pp. 17-20.

Verhoogen, E. (2008), “Trade, Quality Upgrading, and Wage Inequality in the Mexican Manufacturing Sector", The Quarterly Journal of Economics, Vol. 123/2, pp. 489530. 